\title{
Hydrological Statistics for Regulating Hydropower
}

\author{
Anders Wörman \\ The Royal Institute of Technology, \\ Sweden
}

\section{Introduction}

This chapter describes the basic statistical tools needed to analyse water availability in the context of hydropower production. The main topics concern the estimation of water availability from autocorrelated and limited records of river discharge and time-series analysis for the purposes of optimising hydropower output and understanding the physicalstatistical effects in regulated river systems.

Conflicting water needs exist in various parts of the world, e.g., the use of water in irrigation, hydropower production and municipal consumption or in sustaining natural biological habitats. Freshwater availability has been identified as one of the most severe near-term problems (Niijssen et al., 2001; Alley, 2004; Barnet, et al., 2005; National Science and Technology Council, 2004). Furthermore, to counteract global warming, there is an urgent need to adapt global energy production to use more sustainable energy sources (Frossard et al., 2009; Mo et al., 2006). Globally, hydropower potential is only a limited part of total energy consumption (International Energy Agency, 2010), but it can still play a major role as a regulator of energy production. Renewable energy sources such as wave and wind power or bioenergy are not easily regulated. The intermittent nature of wave and wind power may require special regulation strategies if these energy sources are to make substantial contributions to powering the electrical grid.

A range of factors may limit hydropower potential; these include river discharge and its variation, landscape topography and environmental considerations. Landscape topography controls both the head available, which determines hydroelectric energy yield (see Section 2.1), and the conditions for constructing reservoirs. Additional limiting factors for hydropower potential include technical capacity, e.g., turbine design, limitations of the electrical transmission system, technical flaws (failures) and the functionality of the energy market (demand fluctuations). The implication is that water availability alone does not determine the potential for hydropower nor uncertainties in its estimated potential. This chapter, however, is dedicated to evaluating the statistical basis for analysing hydropower potential by considering river discharge and reservoir regulation, and neglecting these other possible limitations.

The annual mean discharge of rivers limits the overall energy output from hydropower plants. Often, however, discharge records are comparatively short and subject to 
fluctuations over different periods that may persist for several years. Time series that exhibit such systematic variations in addition to completely random fluctuations are said to be autocorrelated (see Section 3.2). For example, if the data record of an autocorrelated discharge time series is too limited, there is a risk that the record may represent a comparatively dry or wet period that is not representative of the long-term average. Fluctuations in discharge records are generally also characterised by different typical periods. This study is concerned with both annual and short-term river discharge statistics. The uncertainties in their estimation depend on the annual variation, decadal discharge trends and the length of the time series available. Time-series analysis offers methods by which overall trends and cyclic patterns can be analysed. The information obtained from time-series analysis can be used to forecast the future evolution and describe the overall statistical behaviour of river discharge.

\section{River regulation for hydropower use}

\subsection{Physical characteristics of water regulation for hydropower use}

The availability of water is primarily controlled by the level of precipitation. However, due to evaporation and deep infiltration, not all precipitation becomes runoff and river discharge. The percentage variation in runoff - the basin discharge coefficient - typically varies widely, ranging from less than $20 \%$ to close to $100 \%$ (Chow, 1988; Dunne and Leopold, 1978). Furthermore, temporary storage of water in the river basin introduces significant distortion of the precipitation time series when translated into river discharge. In rural watersheds, the water balance can be expressed by the following relationship (Lascano and van Bavel, 2007; Oki and Kanae, 2006):

$$
Q_{R}=A_{W}(P-E T-D)-d S / d t
$$

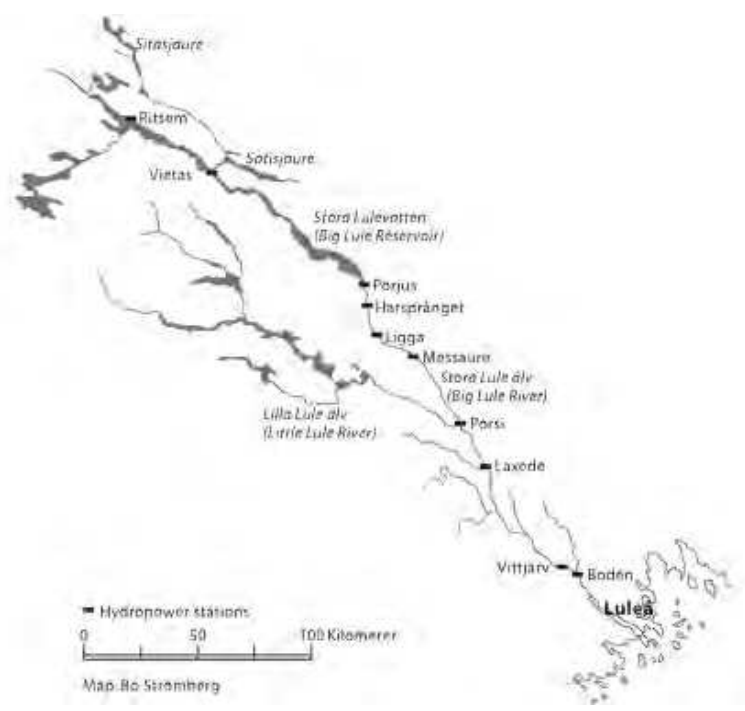

Fig. 1. A map showing the series of hydropower stations along the Luleälven River and the major upstream regulation reservoirs. 
Here, $Q_{R}$ is the river runoff from the watershed $\left(\mathrm{m}^{3} / \mathrm{s}\right), \mathrm{P}$ is the level of precipitation $(\mathrm{m} / \mathrm{s})$, ET is the level of evapotranspiration $(\mathrm{m} / \mathrm{s}), \mathrm{A}_{W}$ is the area of the watershed $\left(\mathrm{m}^{2}\right), \mathrm{D}$ is the net groundwater discharge $(\mathrm{m} / \mathrm{s})$ and $\mathrm{dS} / \mathrm{dt}$ is the rate of change of water storage in the watershed with respect to time $\left(\mathrm{m}^{3} / \mathrm{s}\right)$, where $S$ is the amount of storage $\left(\mathrm{m}^{3}\right)$. The river runoff $Q$ is the total flow of water that can be used for irrigation, hydropower generation and sustaining biota, especially aquatic ecosystems. The actual discharge available for hydropower production is, therefore, limited by these competing needs and the temporal availability of water.

In addition to discharge, the potential power $\mathrm{P}(\mathrm{W})$ of a hydropower plant depends on the average gross head of water assessed for the specific site (i.e., the head of water that can be utilised at the site, $\mathrm{m})$ and the efficiency of the plant $\eta(-)$ according to

$$
\mathrm{P}=\eta \mathrm{QP}_{\mathrm{P}} \rho \mathrm{g} \mathrm{h}
$$

where $\rho$ is the density of water $\left(\mathrm{kg} / \mathrm{m}^{3}\right)$, and $\mathrm{g}$ is the acceleration due to gravity $\left(\mathrm{m} / \mathrm{s}^{2}\right)$. The gross head, $\mathrm{h}$, is a landscape-specific factor but can be altered by constructing a dam that localises the loss of head at the power plant. A reservoir has the dual purposes of creating gross head and storing water (see Section 2.3). Because hydroelectric turbines have limited capacities, an upper limit to the discharge generally exists, which is much lower than the peak discharge of the river. This implies that a portion of the annual river discharge is a spill discharge, $\mathrm{Q}_{\mathrm{S}}$; the remaining portion is utilised for the generation of hydropower, $\mathrm{Q}_{\mathrm{P}}$. The potential power production is that given by the total discharge, i.e. assuming that $Q_{S}=0$.

\subsection{Water regulation strategy}

The potential for hydropower is usually assessed in terms of overall energy output (in units of joules), the maximum suitable installed power generation capacity (in units of watts) and typical variations in power production. Several factors affect this potential, e.g., fluctuations in demand, limitations in the power transfer grid, river discharge fluctuations and the feasibility of water storage and creating a head fall for energy production. Fluctuation in the demand for hydroelectric production depends on behavioural patterns and the extent to which it is possible to operate a hydropower plant in concert with other production sources such as hydropower plants in the same river basin or other power plants.

Figure 2 illustrates the discharge variations over one year at the Vietas hydropower station on the Luleälven River (see Fig. 1) in northern Sweden. The red shaded area in Fig. 2 indicates the volume of water stored in the reservoir during the warm season, when there is less demand for electricity for home heating, and the blue shaded area indicates the volume of water released during the cold season, which is used for electricity production. The volume of water stored during the period of water surplus varies between years in the interval 3-6 $\times 10^{9} \mathrm{~m}^{3}$, where the upper limit corresponds to the difference in reservoir volume between the lowest and highest permissible reservoir levels.

From Eqn. (2), the stored energy E can be expressed as $E=\eta \mathrm{V} \rho g h$, where $\mathrm{V}$ is the volume of water. Using this relationship, we calculated the annual energy storage in this single reservoir to be somewhat less than 1 TWh or approximately $1.5 \%$ of the total annual hydropower production of Sweden. Without the storage volume of the reservoir, large quantities of water would have to be spilled when they are not directly required for 
generation, causing a corresponding energy deficiency during the periods when energy is needed.

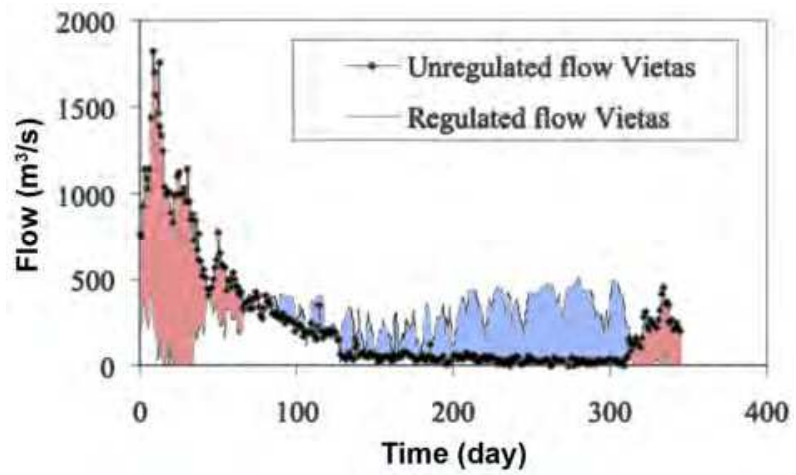

Fig. 2. Example of the flow pattern after regulation of the Luleälven River. The figure shows the observed regulated discharge and the estimated unregulated discharge at Vietas. The period illustrated is from June 20, 2000 to May 31, 2001 (adapted from Jonsson and Wörman, 2005).

This example shows that water availability for hydropower production depends significantly on the timing of 1) energy needs, 2) runoff statistics and 3) water storage. The interactions of such factors are commonly analysed using simulation models for the economic optimisation of power production (see Section 4). Furthermore, water storage in a reservoir affects all hydropower plants located downstream of the reservoir. Such storage generally has only a minor impact on the annual mean discharge (due to its effect on evaporation) but can have a major impact on the temporal fluctuations in water availability and, therefore, on the economic potential of hydropower. Each hydropower plant is associated with a specific time-lag distribution between the release and arrival of discharged water. When water is released from the Suorva Reservoir, there is practically no time lag for the Vietas hydropower station, whereas all 8 units located downstream are subject to various degrees of time lag, with times ranging up to weeks for the entire river (see Fig. 1). The availability of water for power production is, therefore, dependent on the coordination of the power plants and reservoirs within the river basin and, to some extent, on operations occurring between river basins and other energy sources on the grid.

\subsection{Energy output}

The rate of change of the reservoir volume with time can be expressed as a balance between the river inflow and outflows through power production and spillways as follows:

$$
\frac{d V}{d t}=Q_{R}-Q_{P}-Q_{S}
$$

Because the reservoir volume is a function of the head, of the form $\mathrm{V}=\mathrm{A} \mathrm{h}$, the power as expressed by Eqn. (2) depends on both the storage head (i.e., h) and the water discharge 
used for production ( $\mathrm{QP}_{\mathrm{P}}$, where A is the reservoir area. By substituting Eqn. (2) into Eqn. (3) and assuming zero spill $\left(Q_{S}=0\right)$, we obtain a relationship that can be used to optimise energy output:

$$
Q_{R}(t)=\frac{P(t)}{\eta \rho g} \frac{1}{h(t)}+A \frac{d h(t)}{d t}
$$

This is a first-order differential equation with variable coefficients that has no general solution, except for specific variation of the coefficients $Q_{R}(t)$ and $P(t)$. However, we can derive some insight into the physical-statistical nature of the problem by analysing the special case of a stepwise constant power function, i.e., where $\mathrm{P}(\mathrm{t})$ is a constant. For this analysis, we assume no river inflow $\left(Q_{R}=0\right)$ and, as a compensation, introduce an initial increment in the water level on the form $h\left(t=t_{i}+\delta\right)=h\left(t=t_{i}\right)+\Delta R$, where $i$ is a time step, $\delta$ is an infinitesimally small change in time and $\Delta \mathrm{R}\left(\mathrm{t}_{\mathrm{i}}\right)$ is the elevation change due to river inflow; $\Delta \mathrm{R}\left(\mathrm{t}_{\mathrm{i}}\right)=\mathrm{Q}_{\mathrm{R}}\left(\mathrm{t}_{\mathrm{i}}\right) \Delta \mathrm{t} / \mathrm{A}$ and $\Delta \mathrm{t}=\mathrm{t}_{\mathrm{i}+1}-\mathrm{t}_{\mathrm{i}}(>>\delta)$. Hence, the solution becomes

$$
h\left(t_{i}<t<t_{i+1}\right)=\sqrt{2}\left(\frac{\left(\Delta R_{i}+h_{i}\right)^{2}}{2}-\frac{P_{i}}{A \eta \rho g} \Delta t\right)^{1 / 2}
$$

Because the energy output for each time step $E_{i}=P_{i} \Delta t$, we can express the total energy output as the sum over all time steps $\mathrm{N}$. By evaluating the limit when $\Delta t$ tends to zero, hence neglecting higher-order terms (containing $\left.(\Delta t)^{2}\right)$, we obtain

$$
E=\sum_{i=1}^{N} E_{i}=\eta \rho g\left[A \frac{h_{0}^{2}-h_{N}^{2}}{2}+\int_{0}^{T} Q_{R}(t) h(t) d t\right]
$$

where $T=t_{N}-t_{1}$. The second term on the right-hand side of Eqn. (6) follows directly from Eqn. (2), but here we can see that this result is consistent with a fluctuating production, regardless of the $\mathrm{h}(\mathrm{t})$ curve described by the regulation.

Because the long-term change of the reservoir level should normally be zero (i.e., $h_{0}^{2}-h_{N}^{2}=$ 0 ), we can identify the second term as the main source of energy. The integrand represents a product of the arithmetic averages of the discharge $Q_{R}$ and the reservoir head $h$ plus the cross-correlation between the river inflow and reservoir head. In other words,

$$
E=\eta \rho g T\left(E\left[Q_{R}\right] E[h]+\operatorname{Cov}\left[Q_{R}, h\right]\right)
$$

where $E[\ldots]$ is the expectation operator, $\operatorname{Cov}[\ldots]$ is the covariance operator (defined as $\left.\operatorname{Cov}\left[Q_{R}, h\right]=E\left[\left(Q_{R}-\mu_{Q R}\right)\left(h-\mu_{h}\right)\right]\right)$, and $\mu$ denotes an arithmetic mean value (of $Q_{R}$ and $h$, respectively). Consequently, maximising the energy output requires maximisation of both the product of the mean values and the cross-covariance of the discharge and reservoir level. Maximising the cross-covariance means that the frequencies in the river discharge should be followed by corresponding variations in the reservoir elevation. Consequently, relevant discharge statistics in hydropower contexts involve both correlation properties and Fourier spectra. 


\section{Analysis of discharge time-series and the characteristics of regulated rivers}

\subsection{Frequency and return period}

Frequency and return period are common tools used in the analysis of river discharge (Raghunath, 2006). The probability that a river discharge is lower than the discharge at a certain percentile $\mathrm{p}$ is given by

$$
P\left(Q_{R}<Q_{R, p}\right)=\int_{Q_{R}=0}^{Q_{R, p}} f\left(Q_{R}\right) d Q_{R}
$$

in which $\mathrm{f}$ is the frequency function. Eqn. (8) can be conceived of as a definition of both the frequency function and the percentile (which is a number between 0 and 1). The frequency function has the inverse units of discharge and, hence, can be defined for discharge data representing different time intervals such as daily or annual maximum discharge (Fig. 3). The frequency function can thus be calculated for data covering a specific time interval, as shown in Fig. 4 for the Dalälven River, Sweden. Typically, the regulation of river discharge implies an alteration of its discharge statistics. Because the Dalälven River has been regulated for the purposes of hydropower production since 1922, when Lake Siljan was first used as a reservoir, a shift in the frequency distributions after regulation commenced is clearly evident.

Given a specific time interval of the data series, the corresponding return period $T_{R}$ is given by (Chow, 1988):

$$
\mathrm{T}_{\mathrm{R}}=\left[1-\mathrm{P}\left(\mathrm{Q}<\mathrm{Q}_{\mathrm{p}}\right)\right]^{-1}
$$

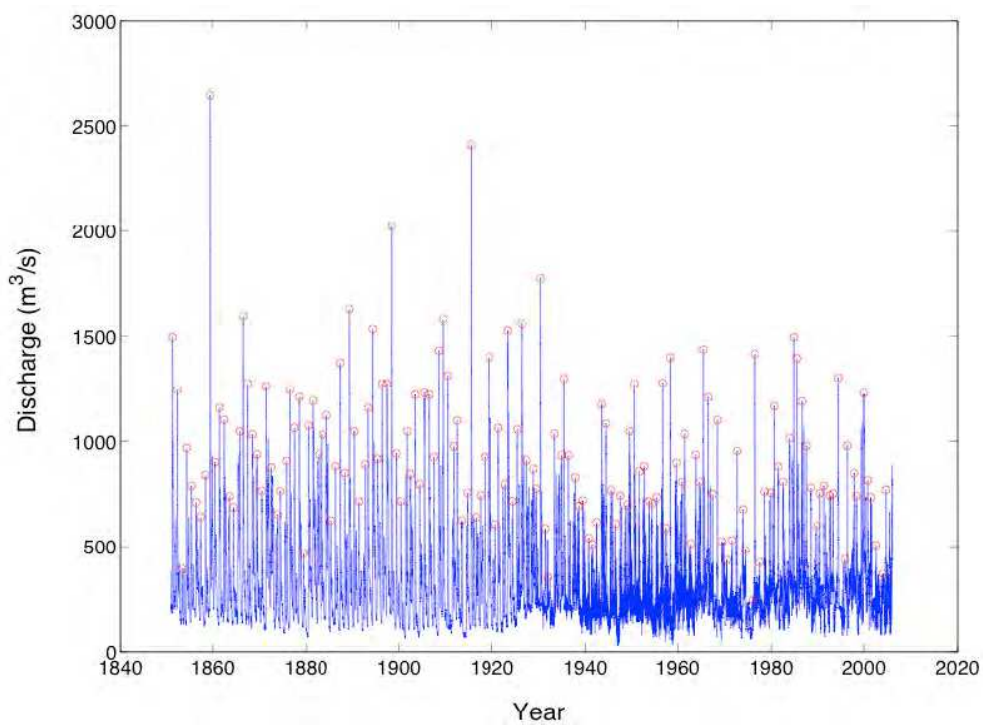

Fig. 3. Discharge time series from the Dalälven River at Fäggeby, Sweden. The blue curve represents daily data, and the red dots represent annual maxima. 


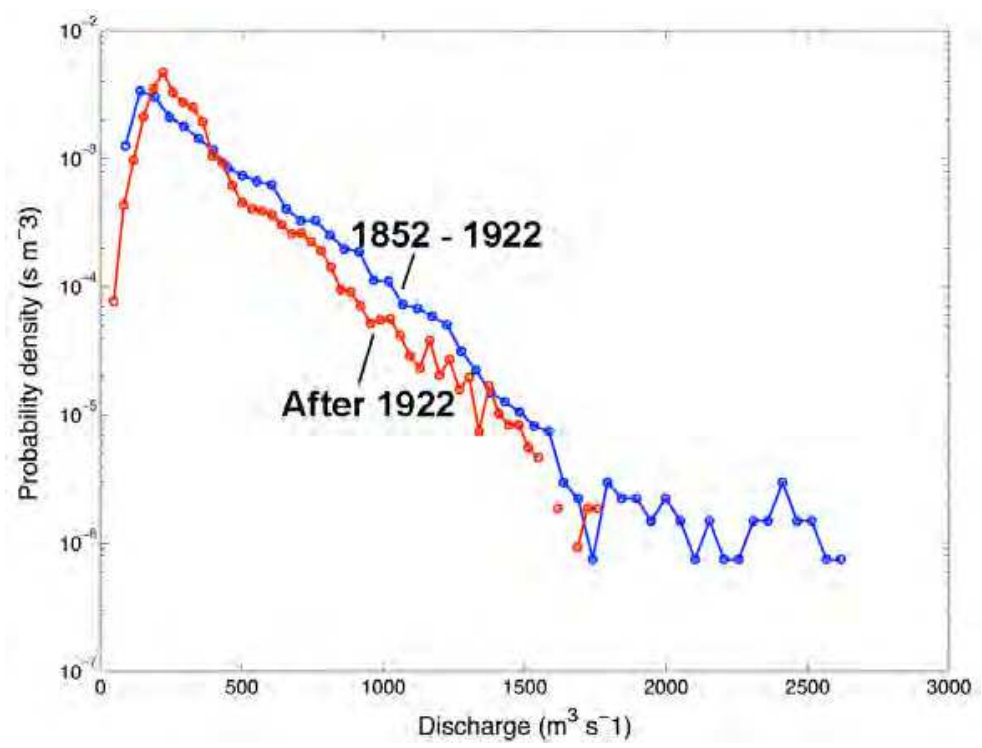

Fig. 4. Frequency distribution for the daily discharge in the Dalälven River at Fäggeby before and after regulation commenced in the early 1920s.

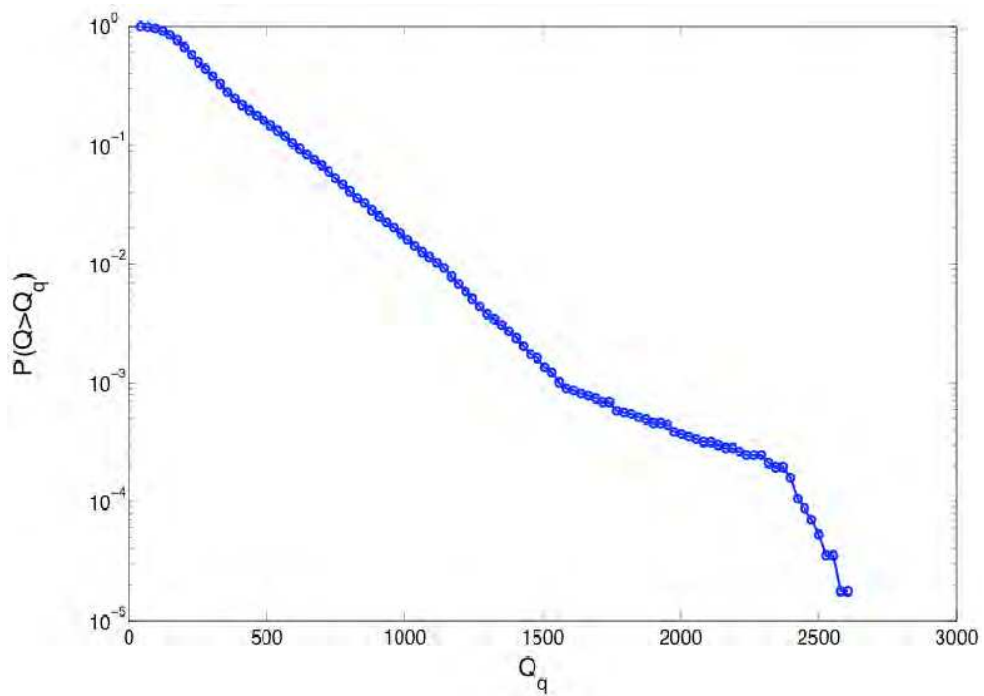

Fig. 5. The probability that the daily discharge exceeds the pth percentile $Q_{p}$.

It is also possible to use the probability for the complementary event that the discharge at the pth percentile is exceeded, i.e., $\mathrm{P}\left(\mathrm{Q}>\mathrm{Q}_{\mathrm{p}}\right)=\left[1-\mathrm{P}\left(\mathrm{Q}<\mathrm{Q}_{\mathrm{p}}\right)\right]$. The maximum $\mathrm{Q}_{\mathrm{p}}$ obtained during this long record, starting in 1852, is somewhat more than 2,500 $\mathrm{m}^{3} / \mathrm{s}$. At $Q_{p}=2,500$ $\mathrm{m}^{3} / \mathrm{s}$, the corresponding $\mathrm{P}\left(\mathrm{Q}>\mathrm{Q}_{\mathrm{p}}\right)=5.5 \times 10^{-5}$, and the return period is $\mathrm{T}=18,182$ days (or 50 years). Consequently, even very long records of discharge data seldom empirically cover 
the range of return periods considered to ensure the structural safety of dams. Because typical design considerations may assume a return period of 1,000 years or even longer, distributions must generally be extrapolated, and predictions using runoff models (Nash and Sutcliff, 1970; Saleh et al., 2000; Lindström et al., 1997) must also be extrapolated outside of the calibration intervals (Seibert, 2003). The time series may be sufficiently long, however, for the consideration of extreme events when planning hydroelectric production.

\subsection{Correlations and the uncertainty of estimates}

As discussed in Section 2.2, the cross-correlation between the river discharge and the reservoir level is a key statistical property for the regulation of river discharge. More generally, autocorrelation represents the covariation of properties over time. Not only is this autocorrelation essential for the estimation of statistical measures for time series, but river regulation also specifically aims at altering the auto-covariance in discharge. The autocovariance in discharge is defined as

$$
C_{Q R Q R}(t, s)=E\left[\left(Q_{R}(t)-\mu_{Q R}(t)\right)\left(Q_{R}(t+s)-\mu_{Q R}(t+s)\right)\right]
$$

where $\mathrm{s}$ is a time lag. The expectation operator can be obtained either as an integration over a known frequency function $\mathrm{f}\left(\mathrm{Q}_{\mathrm{R}}\right)$ or as a summation over discrete samples (Chatfield, 2004; Chow, 1988).

If the lag $s=0$, Eqn. (10) defines the variance, which means that the covariance always adopts the variance $\mathrm{V}_{\mathrm{QR}}$ at $\mathrm{s}=0$ and decays with increasing $\mathrm{s}$. As illustrated in Fig. 6, this behaviour is demonstrated for the discharge of the Dalälven River, Sweden in terms of the following autocorrelation:

$$
r\left(Q_{R}\right)=\frac{C_{Q_{R}}(t, s)}{\sigma_{Q_{R}}(t) \sigma_{Q_{R}}(s)}
$$

where $\sigma$ is the standard deviation.

Fig. 6 demonstrates that the autocorrelation of the discharge in the Dalälven River is cyclic. The periodicity of the discharge is specific for the geographic area and is of significant importance for the estimation of expected values such as the mean or covariance. If the expectation operation is performed for data obtained during a limited period that is not representative of a long time series, the estimation of the mean values becomes uncertain. In the left panel of Fig. 6, we observe that the autocorrelation function for the daily discharge decreases continuously over one year, reflecting seasonal correlations, whereas for longer time lags, the autocorrelation displays a cyclic behaviour, for which the envelope slowly decays with time over several decades. In the annual average data (the right panel of Fig. 6), there is also a continuous decrease of the autocorrelation function for an initial period that is succeeded by a period with more erratic, cyclic behaviour. The uncertainty of the mean of an autocorrelated discharge time series can be expressed as follows (Ballesta, 2004; Zhang, 2005):

$$
u_{Q_{R}}^{2}=\operatorname{Var}\left[\bar{Q}_{R}\right]=\left(1+\sum_{i=1}^{n-1}\left(1-s_{i} / T\right) C_{Q_{R}}\left(s_{i}\right)\right) \frac{\sigma_{Q_{R}}^{2}}{n}
$$



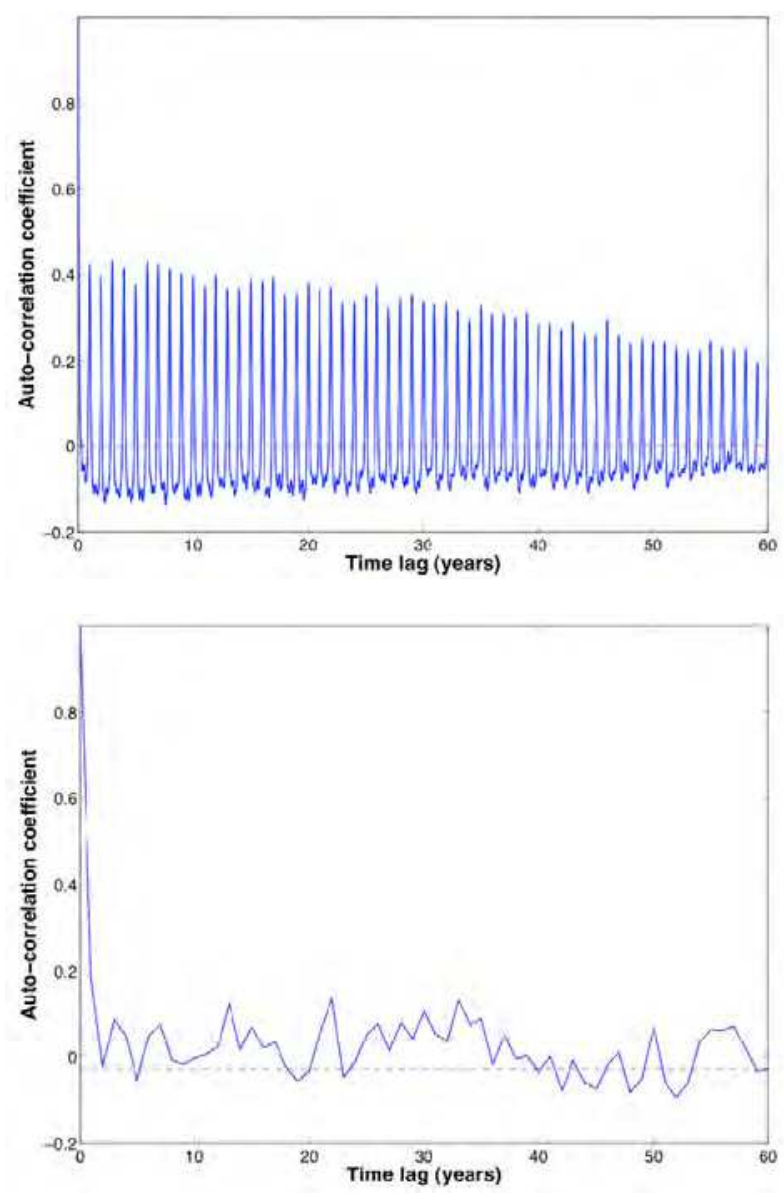

Fig. 6. Autocorrelation coefficients for the daily discharge (left) and the annual average discharge (right) in the Dalälven River at Fäggeby, Sweden.

where $\bar{Q}_{R}$ is the estimated arithmetic mean, $\mathrm{s}$ is the lag in the data from the first data point, and $\mathrm{T}$ is the total interval of the data (the duration) used to estimate the mean value. Thus, the total number of samples affects the uncertainty, as does the sampling duration. For a nonautocorrelated time series, the uncertainty of the estimated mean becomes $\operatorname{Var}\left[\bar{Q}_{R}\right]=\sigma_{Q_{R}}^{2} / \mathrm{n}$, which is therefore the least possible uncertainty. In a practical management plan for hydropower regulation, the available time series is limited; sometimes, in a statistical sense, the series is too limited for reliable estimation of any of the properties on the right-hand side of Eqn. (12). Such incomplete sampling makes estimation of the uncertainty itself uncertain, as discussed by, e.g., Ballesta (2005).

Due to the inter-annual autocorrelation of discharge, there is a significant fluctuation of the standard deviation of the discharge when it is assessed over a limited time window $\mathrm{T}$. This behaviour can be demonstrated by dividing a multidecadal time series into limited time 
windows and assessing the statistical properties in terms of the mean and variance for each window (i.e., examining the intra-window properties). The solid curve in Figure 7 represents the coefficient of variation of the annual mean discharge, which increases slightly with the length of the assessment time window. In addition, the bounds of the maximum and minimum values assessed for the intra-window coefficient of variation tend to converge, which reflects an increased accuracy of the assessed coefficient of variation with a longer assessment window (or a greater number of samples). As shown in Fig. 7, the time window would have to be greater than 20 years for the minimum and maximum estimates to converge with a relative deviation from the mean of less than approximately $10 \%$ in the daily data series (Syrstad and Fäggeby). For the monthly data obtained at Gilgel Abay, the number of samples in the time window is significantly smaller than in the daily time series. This causes a larger uncertainty in the result. Consequently, the data series can be smoothed (averaged) over a sub-window, e.g., one day or one month, with significant consequences for any statistical property. This type of smoothing is discussed in Section 3.2.

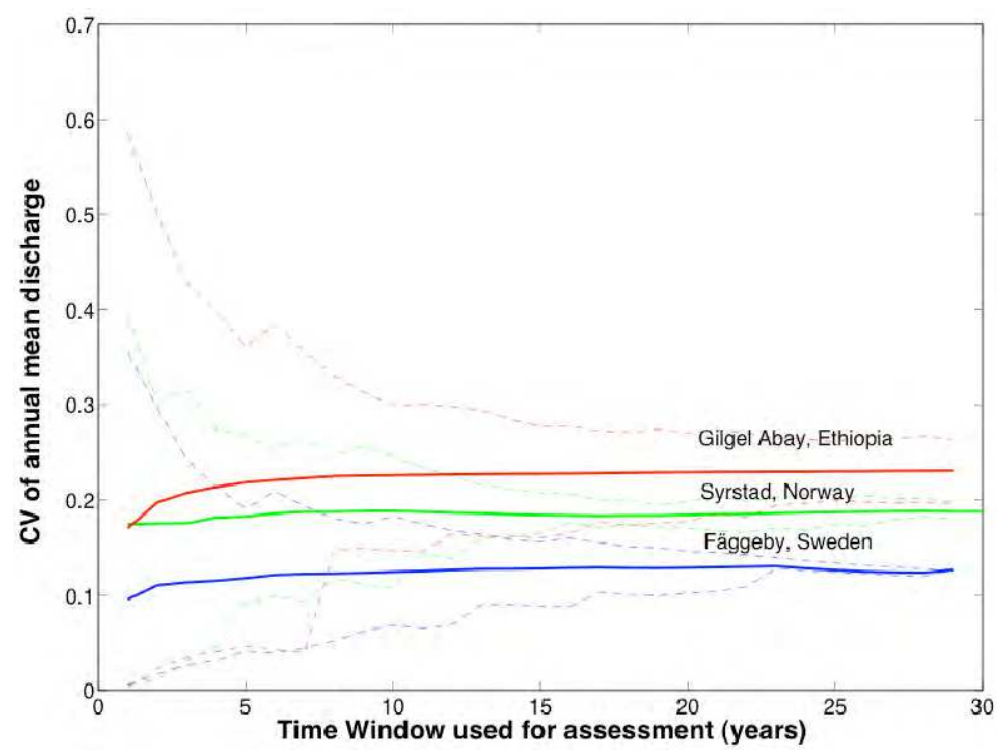

Fig. 7. The coefficient of variation (CV) of annual discharge as a function of the assessment window length at three locations. The dashed curves indicate the lower and upper bounds of the $\mathrm{CV}$ assessed for each time window, ranging over the entire available time series. Solid curves indicate the mean of all assessed CVs. Station Fäggeby is located on the Dalälven River, Sweden, and the daily discharge record used here extends from 1852-2006. Station Syrstad is located on the Orkla River, Norway, and the daily data used here extend from 1974-2008. Station Gilgel Abay is located on a tributary of the Blue Nile in Ethiopia, and the monthly discharge record used here extends from 1973-2002.

In addition to smoothing, the uncertainty and auto-covariance in the discharge time series is affected by variations in the underlying meteorological and hydrological conditions. Because the flow network structure in watersheds tends to smooth the highly intermittent 
(erratic) nature of rainfall, the autocorrelation of discharge increases with the size of the river basin (Wörman et al., 2010; Rinaldo et al., 1991). Figure 8 compares the autocorrelation of a sub-basin for the River Dalälven at Fäggeby with that of an even smaller sub-basin at Ersbo. Typically, the time rate of change of natural variations tend to be smaller with increasing size of the watershed, which is reflected in the increase in autocorrelation with size. Furthermore, the main aim of regulating rivers is to alter natural flow variations; this alteration is manifested both in the autocorrelation function (Wörman et al., 2010) and the frequency function, as discussed in Section 3.1.

\subsection{Auto-regressive representation of discharge time-series}

Discharge time series can be represented by what are termed auto-regressive, moving average (ARMA) models (Chatfield, 2004). Such models can be used to predict the evolution of time series, but can also be conceived of as a "smoothed" representation of the time series. An auto-regressive (AR) model of order $\mathrm{p}$ for a discharge time series can be written as

$$
Q_{R, t}=Q_{R, 0}+\sum_{i=1}^{p} \alpha_{i} Q_{R, t-i}+\varepsilon_{t}
$$

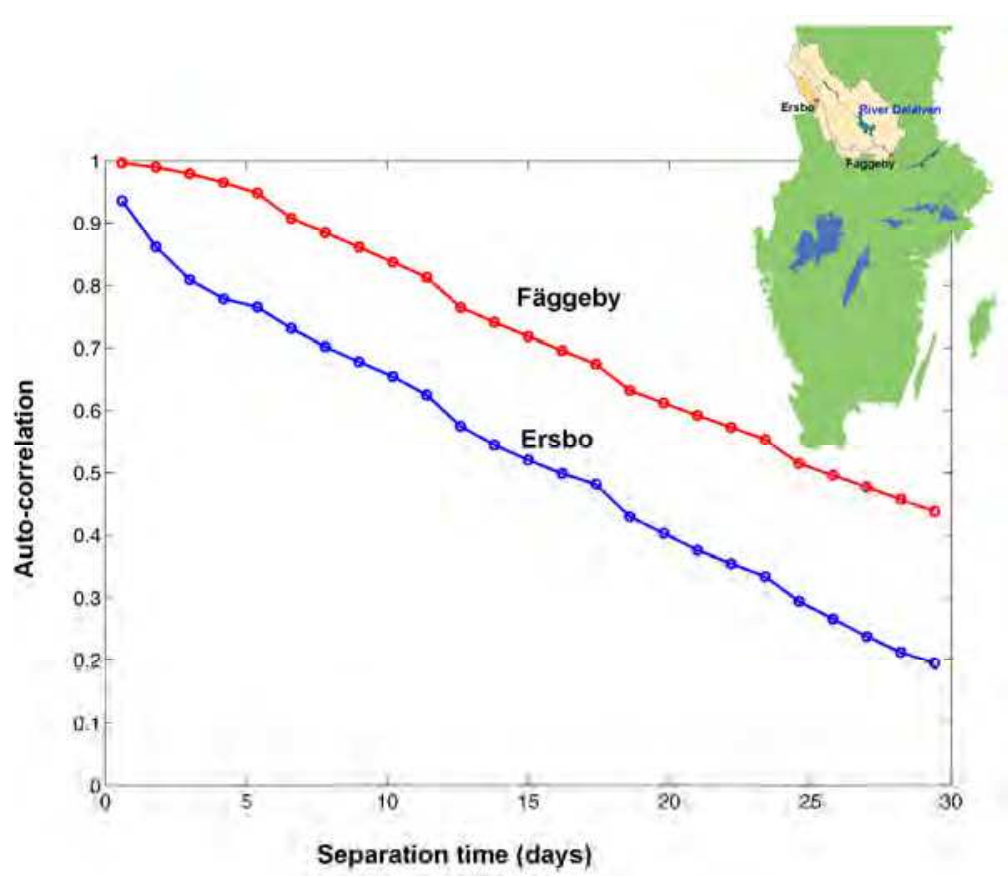

Fig. 8. The auto-correlation function for the discharge at two sub-basins of the Dalälven River.

in which $\mathrm{Q}_{\mathrm{R}, 0}$ is an initial constant, $\mathrm{t}$ is a time index (an integer value), the $\alpha$ terms are coefficients and $\varepsilon$ is the deviation from the trend curve, i.e., an error. Consequently, Eqn. (13) represents a functional variation of the discharge that carries a memory (i.e., is smoothed) 
within the time window associated with the order $\mathrm{p}$. In particular, the second two terms on the right-hand side of Eqn. (11) represent the functional trend or the smoothed discharge:

$$
\tilde{Q}_{R, t}=Q_{R, 0}+\sum_{i=1}^{p} \alpha_{i} Q_{R, t-i}
$$

One example is obtained using constant $\alpha$-coefficients, $\alpha_{i}=1 / p$, by which the smoothed discharge is given as an arithmetic average discharge in a moving window defined by the pth order. The individual data points can be represented in relation to the smoothed curve by adding the appropriate error terms to yield the auto-regressive, moving average (ARMA) model

$$
Q_{R, t}=\tilde{Q}_{R, t}+\sum_{i=0}^{q} \beta_{i} \varepsilon_{t-i}
$$

This is useful in the stochastic predictive mode of a time series, whereas the error term is numerically generated. For example, a purely random-walk type of discharge representation is obtained for $\mathrm{p}=\mathrm{q}=0$, implying that $\mathrm{Q}_{\mathrm{R}, \mathrm{t}}=\mathrm{Q}_{\mathrm{R}, 0}+\varepsilon_{\mathrm{t}}$. In the representation and interpretation of a discharge time series, we are mostly interested in the smoothed discharge. If we assume a time series with zero autocorrelation, the variance of the smoothed discharge is obtained by inserting $\alpha_{i}=1 / p$ in Eqn. (14) and it takes the following form:

$$
\operatorname{Var}\left[\tilde{Q}_{R, t}\right]=\sigma_{Q_{R, t}}^{2} \sum_{i=1}^{p} \alpha_{i}^{2}=\frac{\sigma_{Q_{R, t}}^{2}}{p}
$$

Consequently, if the auto-regressive representation is based on a single value, the variance of the time series is the same as that for the original data. However, the variance decreases linearly as additional data points are added to the smoothing, as exemplified in Fig. 9 for the discharge of the Dalälven River, which compares the variance of the discharge for a moving one-year average, the annual average and the original daily discharge data. Because of the smoothing, it is easier to discern possible trends in the data compared with the highly erratic daily discharge time series. Fig. 10 illustrates the coefficient of variation in the discharge using two time windows for the averaging: three days and one year. The two smoothing techniques reveal the behaviour of the autocorrelated discharge records and the predominance of different frequencies in the time series. Using the one-year window, we observe a decrease in the discharge variance after regulation commenced in the 1920s. However, the short-term variation in discharge simultaneously increased, and this is more clearly seen when using the shorter, three-day time smoothing window. The need to use different time windows (possibly a large number of windows) to reveal the typical behaviour of discharge time series calls for the use of methods other than ARMA models. In particular, if the variance in the data depends on there being different periods of change in the time series, then the standard deviation on the right-hand side of (16) will depend on the order p. Spectral techniques are specifically designed to study periodic behaviours in time series, as discussed in Section 3.4. 


\subsection{Decomposing hydropower time-series in spectra}

The regulation of rivers for hydropower production implies the alteration of discharge periods rather than the mean or variance of the discharge. The variance can be either positive or negative depending on the time window used for averaging (Fig. 10), which calls for a technique that can specifically differentiate among a distribution of periods in the discharge time series. Spectral techniques offer possibilities for relating typical periods of variation in river discharge, reservoir level (regulation) and electricity production in response to changes in demand. All these time series exhibit typical daily variations due to, e.g., consumption behaviour, and yearly variations due to the seasonality of river discharge. Using a Fourier spectral analysis, we can identify the dominant periods, both short and long, that prevail over a sufficiently long time interval and use this information to statistically evaluate and plan appropriate long-term regulation. However, spectral analysis is not the perfect tool for optimising regulation at a specific point in time in a regulation scheme. Wavelet transforms are also commonly used in hydrological problems (Nakken, 1999) and can be used to identify the variation in spectra over time.

The Fourier transform of a time series $f(t)$ is defined as follows:

$$
\bar{f}[k]=\int_{-\infty}^{\infty} f(t)(\cos (k t)+i \sin (k t)) d t
$$

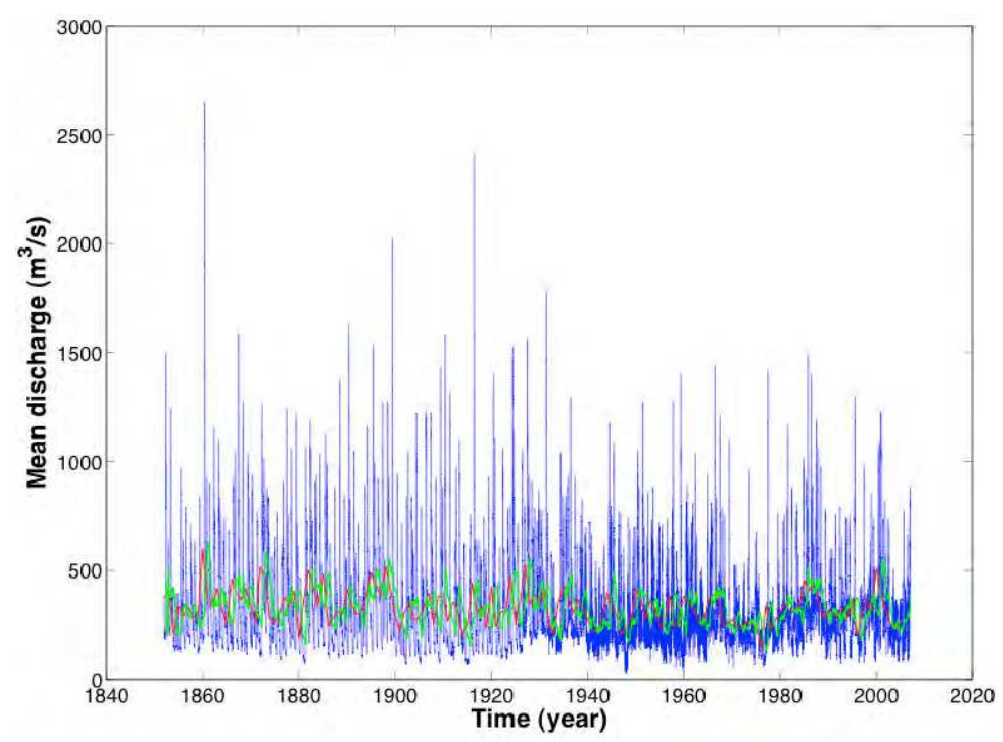

Fig. 9. Mean discharge for the Dalälven River at Fäggeby assessed in three ways. The red curve illustrates the annual average, the green curve illustrates the moving one-year average and the blue curve illustrates the raw daily discharge data. 


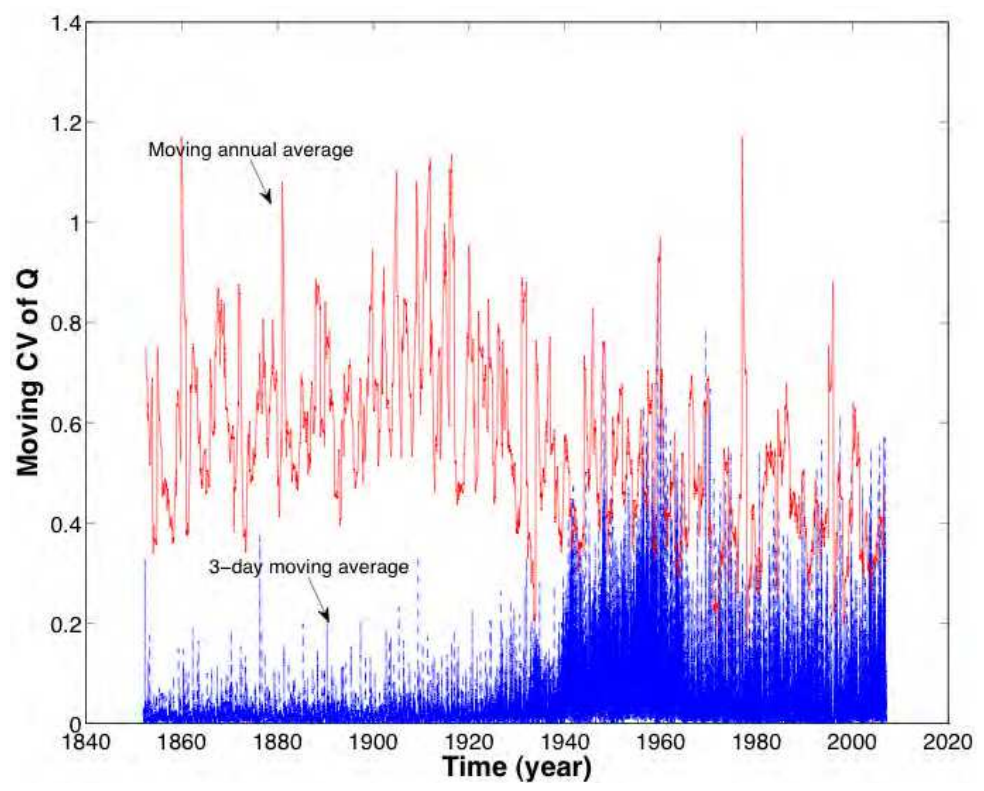

Fig. 10. Coefficient of variation of discharge for the Dalälven River at Fäggeby, assessed as a moving one-year window over daily data and as a three-day moving window of daily discharge data. The coefficient of variation markedly changed after hydropower regulation commenced in the 1920s.

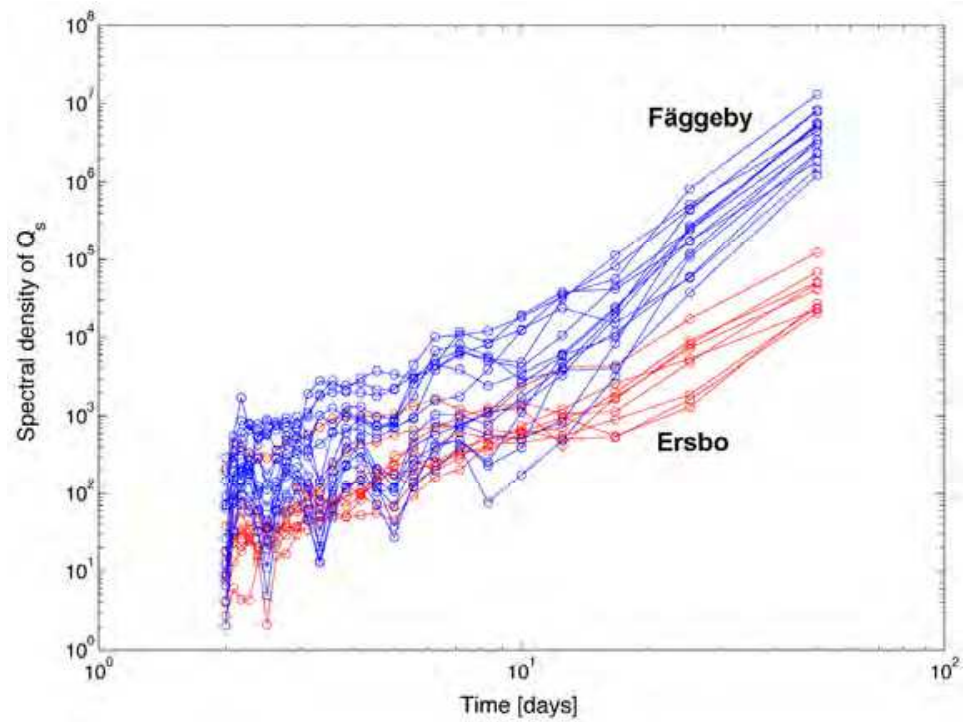

Fig. 11. Spectra derived for various years at two hydrological stations along the Dalälven River. Each curve represents the spectrum from a one-year period distributed along the time series before regulation commenced in the 1920s. 


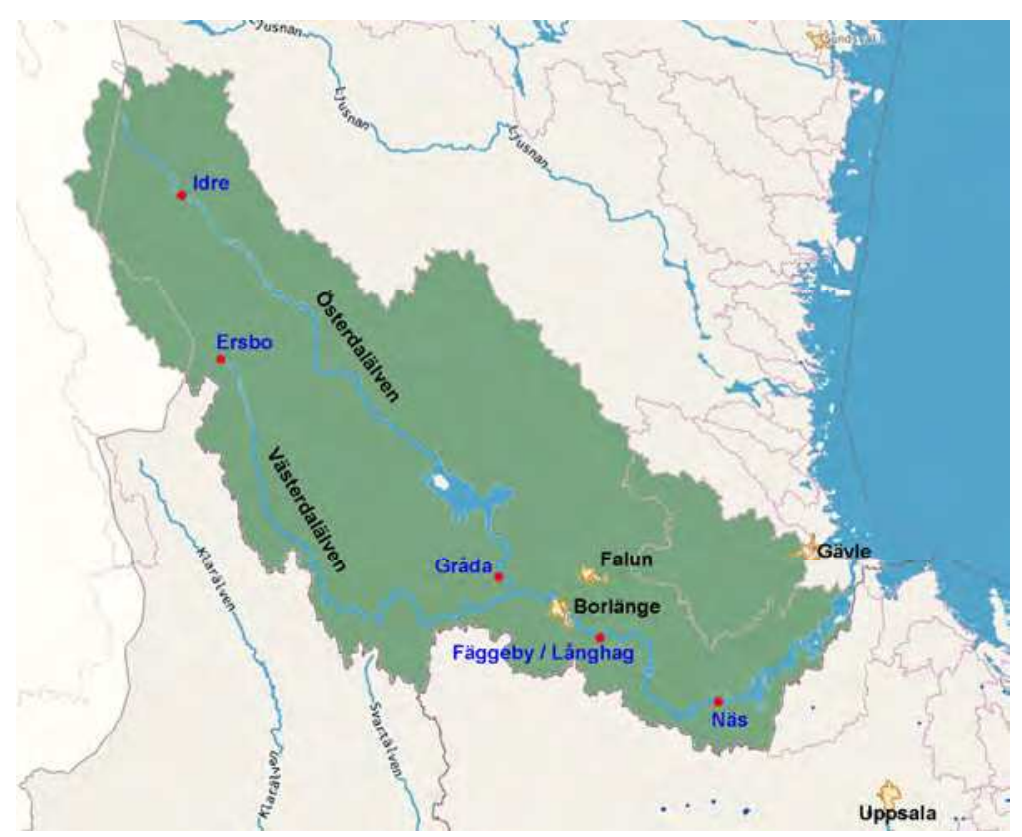

Fig. 12. The Dalälven River Basin and selected hydrological stations. Hydropower plants are located at Gråda, Långhag and Näs.

Here, the wavenumber (frequency) $\mathrm{k}=2 \pi / \lambda, \lambda$ is the wavelength (time period), and $\mathrm{i}$ is the imaginary part of the complex number. This representation makes it possible to study the variation of the time series as a function of the typical wavelengths of periodic functions rather than as the sum of all periodic functions. Specifically, the power spectrum is given by

$$
P(k)=\bar{f}(k) \cdot \bar{f}(k)^{*}
$$

where the superscripted star denotes the complex conjugate and is introduced to obtain a real-valued spectrum. The power spectral density is defined as $P(k) / 2 \Delta k$. Both the power spectrum and the spectral density represent the relative contributions of various wavelengths to the original (real) time series. An advantage, but also a limitation, of the Fourier spectrum is its periodic nature, which makes it possible to directly observe repeated patterns such as self-similarity or fractal distribution in the periodic functions. The power spectrum reflects the relative importance of short and long return periods for the flow and, hence, indicates the degree of periodicity and the randomness of the water-flow time series. A steeper spectrum implies a more organised return-period pattern, whereas a completely flat spectrum reflects white noise (fully random). It is known that river basins have fractal network properties and that this geometric structure consistently organises runoff time series (Rodriguez-Iturbe and Rinaldo, 1997; Snell and Sivapalan, 1994).

Fig. 11 presents the power spectrum of river discharge evaluated at the two stations shown in Fig. 12, Ersbo and Fäggeby. The discharge was evaluated for various years to demonstrate the consistency of the results and the systematic difference in spectral slopes. The slope of 
the discharge spectrum is significantly steeper for the larger river basin defined by the station at Fäggeby than for the discharge spectrum from the sub-basin defined by the station at Ersbo. This result is consistent with the difference between the autocorrelation spectra shown in Fig. 8. The spectra in Fig. 11 are almost fractal because they follow the power law $\mathrm{P}(\mathrm{k}) \sim \mathrm{k}^{\mathrm{a}}$, where a is a constant exponent. These fractal properties change with systematic alterations of the landscape runoff characteristics and river regulation (Wörman et al., 2010). Previous studies have indicated that climate change may have significant effects on the mean runoff in many parts of the world (e.g., Bergström et al., 2001; Vörösmarty, et al., 2000; Lindström and Alexandersson, 2004). Specifically, physical simulation studies have indicated a long-term relationship between climate change and hydrological time series, which manifests as an alteration of the power spectrum (Blender and Fraedrich, 2006).

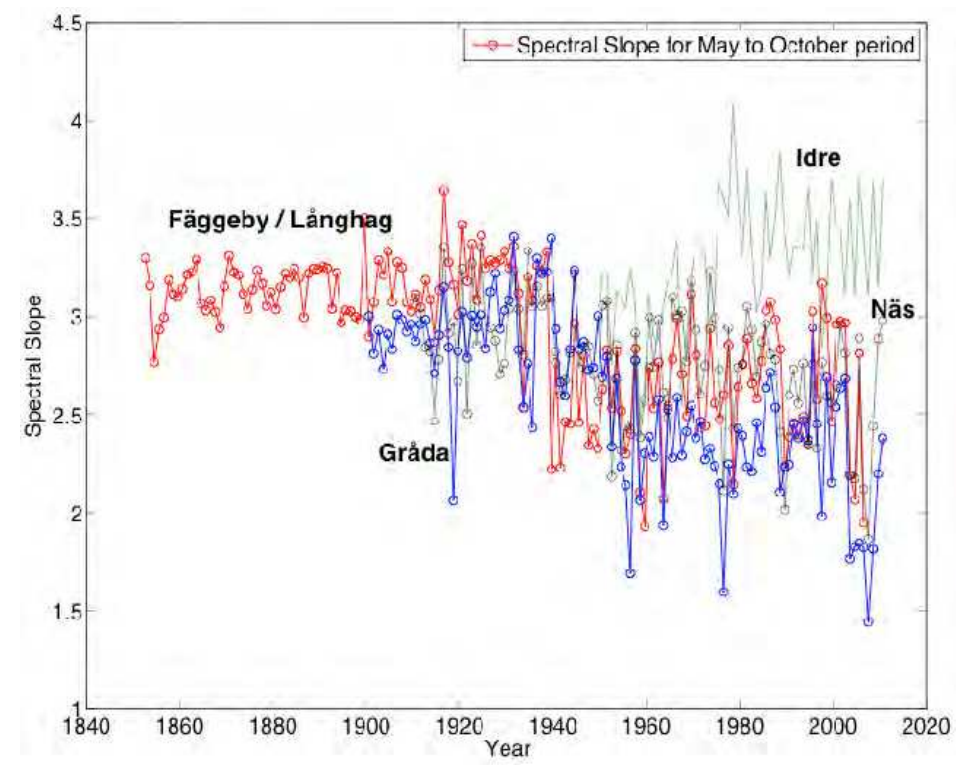

Fig. 13. Evolution of the discharge spectral slopes at selected hydrological stations along the Dalälven River during the 20th century. The spectral slope is evaluated based on one-year data intervals (January to December).

The change in the discharge spectral slopes over time at several hydrological stations along the Dalälven River is illustrated in Fig. 13. Similar to the results obtained during the variance analysis (Fig. 10), the discharge spectra illustrated here demonstrate sudden, significant changes (generally a reduction of the slope) at the time when hydropower regulation was introduced. This behaviour is evident in the results obtained for the hydropower stations at Gråda, Långhag and Näs but is not seen in the results obtained for the station at Idre, which was not affected by regulation. In contrast, at the Idre station, there is a successive increase in the spectral slope, which is generally associated with a change in the drainage capacity of the watershed (Wörman et al., 2010). This led to an inverse relation with time for the discharge spectral slope at Idre compared to those for the stations further downstream. 


\section{Optimisation of energy output}

One aim of hydropower production is to maximise energy output. The estimation of the theoretical potential for hydropower or the optimisation of future production is therefore of interest. The relationships governing the energy output of a river basin hydropower system include the following:

- $\quad$ Power generation as a function of discharge and head, Equation (2)

- The reservoir water balance, Equation (3)

- Information regarding reservoir characteristics and the hydraulic behaviour among hydropower plants

- Meteorological and hydrological statistics

- Power demand statistics (energy demand fluctuations)

As stated in the introduction of this chapter, we are only concerned here with energy output and the forcing due to fluctuations in power use and hydrological conditions. In a market economy, electricity is bought and sold, and power production is generally optimised with respect to the profit generated by industrial activity. This market effect can include price fluctuations based on the availability of power and other factors.

Eqns. (2) and (3) can be combined into Eqn. (4) to represent the impact of the forcing power function and river discharge on optimal reservoir management. On the river-basin level, the power and water mass balance equations are defined for each reservoir using the appropriate time lags in water flow. In a daily optimisation scheme for hydropower production, the future behaviour of the forcing functions due to hydrology and power demand are uncertain, which is why such an optimisation should be based on a stochastic description of the forcing time series. When estimating the (maximum) potential for hydropower, it may suffice to consider only the statistical nature of the time series. For the single-reservoir problem, we can demonstrate that these relationships combine to yield Eqn. (7), which includes the mean value of the discharge and reservoir head, and the covariance of these two time series. Eqn. (10) gives the uncertainty in the estimation of the mean of an autocorrelated discharge time series. The importance of the covariance also follows from the spectral analysis, in which we also see the importance of optimising individual periods of the reservoir elevation with the forcing functions associated with variations in river discharge and power demand.

By applying the Fourier transform to Eqn. (4) and multiplying the transform by its complex conjugate, we obtain the following relationship between time-series spectra:

$$
S_{Q_{R}}=\frac{S_{P} * S_{1 / h}}{(\eta \rho g)^{2}}+\omega^{2} A^{2} S_{h}
$$

The convolution between the demand power spectrum SP and reservoir elevation spectrum $\mathrm{Sh}$ is linearly proportional to the convolution of the cross-spectrum $\mathrm{S}_{\mathrm{Ph}}$, i.e. as $\mathrm{SPh}_{\mathrm{Ph}}{ }^{*} \mathrm{~S}_{1 / \mathrm{Ph}}$.

\section{Conclusion}

Statistical methods of hydrology can be used to predict the future evolution of a discharge time series or obtain the typical statistical properties that are important for hydropower planning such as a smoothed representation of the discharge time series, its correlation 
structure and spectral properties. Typical effects of hydropower regulation include a smoothing of the variance in discharge, which leads to a narrower frequency function, longer periods of significant autocorrelation (Wörman et al., 2010) and a lower slope for the power spectrum. The frequency function (Fig. 4) shows an increase in the peak discharge and peak frequency because the flow regulations tend to prefer discharges close to the mean. The higher curvature of the declining limb implies a smaller spreading of the frequency distribution in the middle range of the discharges but can also indicate a flatter and longer tail. Simultaneously, the power spectrum becomes flatter due to regulation (Fig. 13), which means that the discharge is statistically more random than before regulation. The randomness of the discharge time-series increases as the size of the sub-catchment decreases.

The covariance between discharge and reservoir elevation can be identified as a specific contribution to the energy output from a hydropower plant (Eqn. (7)). Thus, the optimisation of hydropower regulation requires consideration of the cross-correlation between river discharge and reservoir elevation. This consideration can be addressed by relating the spectra for reservoir elevation and river discharge to the spectra for power production or demand (Eqn. (19)).

Global awareness is increasing that the predominant use of fossil fuel is a main driver of global warming and that an increase in the use of renewable energy sources is required (International Energy Agency, 2010). However, renewable energy sources such as wind, waves and tides are intermittent and require the balancing of production sources to meet demand during periods of low production. Hydropower is primarily renewable and can be regulated, i.e., energy can be stored in regulation reservoirs. Therefore, it is likely that not only will hydropower play an important role as a renewable energy source in the future but also as an important regulator of the energy system.

\section{Acknowledgements}

The research presented in this thesis was conducted at the Swedish Hydropower Centre (Svenskt Vattenkraftcentrum, SVC). The SVC was established by the Swedish Energy Agency, Elforsk and Svenska Kraftnät, together with Luleå University of Technology, The Royal Institute of Technology, Chalmers University of Technology and Uppsala University.

\section{References}

Alley WM, Leake SA (2004) The journey from safe yield to sustainability. Ground Water 42:12-16.

Ballesta, P.P., 2005. "The uncertainty of averaging a time series of measurements and its use in environmental legislation", Atmospheric Environment 39 (2005) 2003-2009.

Barnet TP, Adam JC, Lettenmaier DP (2005) Potential impacts of a warming climate on water availability in snow-dominated regions. Nature 438:307-309.

Bergström, S., Carlsson,B., Gardelin, M.G., Lindström, G., Pettersson, A., Rummukainen, M. 2001. Climate change impacts on runoff in Sweden- assessments by global climate models. Climate Research 16: 101 - 112. 
Bleander R, Fraedrich K. 2006. Lond-term memory of the hydrological cycle and river runoffs in China in a high-resolution climate model. International Journal of Climatology 26:1547 - 1565., DOI: 10.1002/joc.1325.

Chatfield, C., 2004. "The analysis of Time Series", Chapman \& Hall/CRC, London.

Chow, Ven Te, 1988. Applied Hydrology. Mc Graw-Hill Book Company, New York.

Dunne and Leopold. 1978. Water in Environmental Planning. W.H. Freeman and Company, New York.

Frossard, A., de Lucena, P., Szklom, A.S., Schaeffer, R., 2009. “Renewable Energy in an Unpredictable and Changing Climate", Modern Energy Review, 1(22-25).

Jonsson, K. and Wörman, A.. 2005. "Influence of Hyporheic Exchange on Solute Transport in a Highly Hydropower-Regulated River", Chapter in text book "Water Quality Hazards and Dispersion of Pollutants", Eds. Czernusznko W., Rowinski P.M., Springer, USA, ISBN 0-387-23321-0, pp. 185-213.

Lascano, R.J., van Bavel, C.H.M., 2007. "Explicit and Recursive Calculation of Potential and Actual Evapotranspiration", Agron. J. 99:585-590 (2007)

Lindström, G., Johansson, B., Persson, M., Gardelin, M., Bergström, S., 1997. Development and test of the distributed HBV-96 hydrological model, J. Hydrology, 201:272-288.

Lindström G, Alexandersson H. 2004. Recent mild and wet years in relation to long observation records and climate change in Sweden. Ambio XXXIII(4-5): 183-186.

Mo, B., Doorman, G., Grinden, B., 2006. "Climate Change - Consequences for the electric system", Report no. CE-5, Hydrological Service - National Energy Authority, Iceland, ISBN 9979-68-194-2.

National Science and Technology Council (NSTC) (2004) Science and Technology to Support Fresh Water Availability in the United States. (NSTC, Washington D.C.).

Nakken M. 1999. Wavelet analysis of rainfall-runoff variability isolating climatic from anthropogenic patters. Environmental Modelling and Software 14: 283-295.

Nash, J. E. \& Sutcliffe, J.V., (1970) River flow forecasting through conceptual models part I-A discussion of principles. Journal of Hydrology, 10 (3), 282-290.

Nijssen , B., O'Donnell, G.O., Hamlet, A.F., Lettenmaier, D.P, 2001. “Hydrologic Sensitivity of Global Rivers to Climate Change", Climate Change, 50(1-2), 10.1023/ A:1010616428763.

OECD, 2008. “OECD Key Environmental Indicators 2008”, OECD, Paris, France.

Oki T, Kanae S (2006) Global hydrological cycles and world water resources Science, 313:1068-1072.

Raghunath, H.M., 2006. Hydrology - Principles, Analysis, Design. New Age Int. Lim. Pub., New Dehli.

Saleh, A., Arnold, J.G., Gassman, P.W., Hauck, L.M., Rosenthal, W.D., Williams, J.R. \& McFar-land, A.M.S., (2000) Application of SWAT for Upper North Bosque River Watershed. Trans. ASAE, 45(3), 1077-87.

Rinaldo A, Marani A, Rigon R. 1991. Geomorphological dispersion. Water Resources Research 27(4): 513-525.

Rodriguez-Iturbe I, Rinaldo A. 1997. Fractal River Basin. Cambridge. University Press: United States.

Seibert, J., 2003. Reliability of model predictions outside calibration conditions, Nordic Hydrology, 34: 477-492.

Snell JD, Sivapalan M. 1994. On the geomorphological dispersion in natural catchments and the geomorphological unit hydrograph. Water Resources Research 30(7): 23112323. 
Wörman, A., Lindström, G., Riml., J., Åkesson, A., 2010. “Drifting runoff periodicity during the 20th century due to changing surface water volume", Hydrological Processes 2010, 24(26), 3772 - 3784, DOI: 10.1002/hyp.7810

Vörösmarty CJ, Green P, Salisbury J, Lammers RB (2000) Global water resources: vulnerability from climate change and population growth. Science 289:284-288.

Zhang, N.F., 2005. "Calculation of the uncertainty of the mean of autocorrelated measurements", Metrologia 43 (2006) S276-S281. 


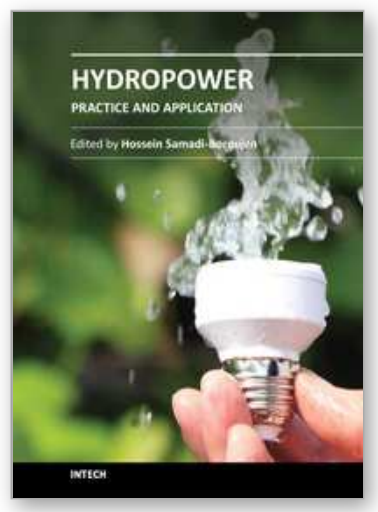

\author{
Hydropower - Practice and Application \\ Edited by Dr. Hossein Samadi-Boroujeni
}

ISBN 978-953-51-0164-2

Hard cover, 320 pages

Publisher InTech

Published online 09, March, 2012

Published in print edition March, 2012

Hydroelectric energy is the most widely used form of renewable energy, accounting for 16 percent of global electricity consumption. This book is primarily based on theoretical and applied results obtained by the authors during a long time of practice devoted to problems in the design and operation of a significant number of hydroelectric power plants in different countries. It was preferred to edit this book with the intention that it may partly serve as a supplementary textbook for students on hydropower plants. The subjects being mentioned comprise all the main components of a hydro power plant, from the upstream end, with the basin for water intake, to the downstream end of the water flow outlet.

\title{
How to reference
}

In order to correctly reference this scholarly work, feel free to copy and paste the following:

Anders Wörman (2012). Hydrological Statistics for Regulating Hydropower, Hydropower - Practice and Application, Dr. Hossein Samadi-Boroujeni (Ed.), ISBN: 978-953-51-0164-2, InTech, Available from: http://www.intechopen.com/books/hydropower-practice-and-application/hydrological-statistics-for-regulatinghydropower

\section{INTECH}

open science | open minds

\section{InTech Europe}

University Campus STeP Ri Slavka Krautzeka 83/A 51000 Rijeka, Croatia

Phone: +385 (51) 770447

Fax: +385 (51) 686166 www.intechopen.com

\section{InTech China}

Unit 405, Office Block, Hotel Equatorial Shanghai No.65, Yan An Road (West), Shanghai, 200040, China 中国上海市延安西路65号上海国际贵都大饭店办公楼 405 单元 Phone: +86-21-62489820

Fax: +86-21-62489821 
(C) 2012 The Author(s). Licensee IntechOpen. This is an open access article distributed under the terms of the Creative Commons Attribution 3.0 License, which permits unrestricted use, distribution, and reproduction in any medium, provided the original work is properly cited. 